\title{
Analyzing Prevalent Internal Challenges to China Pakistan Economic Corridor (CPEC) through Public Opinion
}

\author{
Muhammad Faisal Sultan \\ Assistant Professor KASBIT \& PhD Scholar KUBS-UoK \\ Mohammad Omar \\ Lecturer and Academic Coordinator, KASBIT \\ Rozina Imtiaz \\ Faculty, PAF-Kiet
}

\begin{abstract}
China Pakistan Economic Corridor (CPEC) is the project of high priority, importance and having ability change dynamics of entire world. Though there are some obstructions in the way and if authorities don't treat these effectively then cordial tiers between Pakistan and China might get over. Therefore there is a need of procedures that will end the prevailing negativity in local residents of Pakistan and investors from China. Therefore a contemporary and pervasive study is required to understand issues which are perceived as real barrier to CPEC by the residents of Pakistan. Hence the aim of this study presents a contemporary model of prevailing internal issues perceived important by the residents of Pakistan.
\end{abstract}

Keywords: CPEC, Public Opinion, Challenges \& Pak-China Relationship

DOI: $10.7176 / \mathrm{JESD} / 10-7-01$

Publication date: April $30^{\text {th }} 2019$

\section{Introduction:}

China Pakistan Economic Corridor (CPEC) is treated as game changer not only for China and Pakistan but for the entire region it covers (Riaz \& Mi, 2017). According to Mirza Azem Waheed and Zehra (2017) aim of the project is to strengthen the relationship between two countries. Study further highlighted that CPEC will foster economic development for both of the countries through connecting southwest of Pakistan to the northwest of China. Relating projects particularly to Pakistan study of Ali Ali Ali Raza and Niazi (2018) indicated that out of \$44 billion, \$11 billion are for public investment and $\$ 33$ billion are separated for private investment. Project will also attract other neighboring countries towards the project thus helps Pakistan in coming out of low economic growth and improves life style of its residents.

On the other hand Mengsheng (2015) postulated that for China CPEC has multiple significances as this will help china in solving issues for strategy, security, energy and military affairs etc. Similarly Ahmad and Hong (2017) indicated that "Flagship Project" of China aids its economy through developing shortest route to access Middle-East, Europe and Africa. Study also postulated that successful completion of CPEC aids China in overcoming US dominance from all over the world and will also flourish China's north-western province Xinjiang. Therefore Butt and Butt (2015) recommended that project must be termed as "Crown Jewels". Study further adds that the project will not only foster friendship bond between Pakistan and China but also bring new economic paradigm in the region.

On the contrary study of Deng and Li (2017) posits that progress of CPEC will also increases ratio of import as well as debt from China. Study claims that CPEC will increase overall debt of Pakistan by $\$ 3$ billion which might bring Pakistan to "Circular Model" of economic crises. Similarly article of Khaliq (2018) indicated that CPEC might foster the economy of Pakistan but in the process it might make Pakistan a colony of China. Khaliq also supported Deng and Li that China became largest lender of Pakistan as total debt from China raised to $\$ 19$ billion. According to author CPEC will add approximately $\$ 14$ billion to the debt of Pakistan which makes total debt equal to $\$ 40$ billion by June 2019 . Supported by Aamir (2018) that external debts raised to $\$ 91$ bn from $\$ 74$ billion and foreign currency reserves also fall from $\$ 16.1$ to $\$ 10$ billion in a year time.

\section{Statement of Problem}

Mengsheng (2015) indicated that CPEC has massive importance with respect to strategic perspectives of both China and Pakistan and now it is the largest foreign investment of China (Mirza, Azeem, Waheed \& Zehra, 2017). Durrani Samiullah Khan Irfan and Raza (2017) further clarify that CPEC will not only reduce fuel consumption, transit time, wear and tear etc but also improve living standards of Pakistan's residents. On the other side study of Mengsheng (2015) presented the point that to set objectives of CPEC, China will be looking at the strategies of Pakistan. Similarly Deling and Diren (2015) highlighted that CPEC is subjected to enormous challenges and many Chinese investors have serious reservation on security matters. Study also highlighted the fact that economy of 
Pakistan is much weak to support development of project (Ali et al., 2017). Coupled with an indication that in order to avoid cultural barriers Chinese companies rely more on their own workforce and this might create massive issues in implementation of CPEC (Deng \& Li, 2017).

Thus it is appropriate to believe that journey of CPEC is subjected to various internal and external challenges (Khan, 2018). Hence official must pay attention to policy development to settle issues obstructing the project and any delay in this regard may foster negative perception among local public (Deng \& Li, 2017).

\section{Purpose of Study and Delimitations:}

Purpose of the study is to gain insight regarding issues and challenges which are obstructing the way of CPEC. Although required information is not available as CPEC is still under progress. (Mirza et al., 2017) Hadi Batool and Mustafa (2018) also indicated lacking of primary level research on the topic and demands that future studies must address the concern to benefit stakeholders significantly.

Thus the major objective of the study is to highlight the major obstacles obstructing the way of CPEC through public opinion. The idea of data collection through public opinion is supported by Deling and Diren (2015) that policy makers like to have public opinion to achieve sustainability in their practices. Hence keeping the point of Deling and Diren in view policy makers must device some criteria to match with public reaction. Especially when there is a requirement of paying more attention to issues associated with CPEC \& its implementation (Khan, 2018) to avoid generation of negative perception in local public (Deng \& Li, 2017).

\section{Theoretical Framework}

One of the early studies on CPEC by Abid and Ashfaq (2015) pointed out various internal obstacles e.g. Political Insecurity, Ethnic Separation and Violence etc. Study also highlighted some external factors like India and Iran in creating problems for CPEC coupled with some Chinese's reservation on issues associated with tax and tariff. Ali (2015) also highlighted similar potential obstacles e.g. internal security, ethnic separation, corrupt bureaucracy, lack of trained workforce and external influence of India.

Study of Ali et al (2017) indicated some of the external threats which might hinder the way of CPEC but mostly focused towards the opportunities and benefits of CPEC to economy and residents of Pakistan. Similarly study of Mirza (2017) also studied the potential benefits of CPEC to the economy of Pakistan. Although Ahmad and Hong (2017) indicated some major internal and external challenges e.g. Political and Economic Challenges, Lack of Quality Labor in Pakistan, Internal Security, Ethnic Separation and Influence of India.

Hence from review of literature it has been evident that there are several researches which are highlighting obstacles, issues and challenges to the CPEC. In addition to these studies Javaid (2016) indicated potential threats and Abbas, Shouping, Sidra, and Sharif (2018), Khan (2018) and Shah (2018) indicated some obstacles which were not mentioned by the prior researchers. Therefore keeping all these internal obstacles, issues and problem in view a concrete research model has been developed to predict factors diminishing the progress of CPEC.

However the model is only supplemented with one moderating variable i.e. external influence of India and influence of Iran is not included in the inventory of moderating variables. Similarly protest from China has not been included in the variable inventory of moderating variables. These measures are taken as China's protest is actually due to the internal obstacle \& Iran is obstructing CPEC. Therefore the moderation in the model has been indulged only in a shape of external influence of India.

\section{Significance}

Study is immensely beneficial for policy makers and technocrats to analyze the opinion of those who are primary stake holders of the project (CPEC). Through this study officials might understand the view point that what those elements which are perceived as major hurdle are. Through this study policy makers might optimize their policies to make public believe on policies and point of view of officials and government.

Moreover study is also beneficial for optimizing future research through collecting archival data based upon evidences and proofs rather than opinions. Independent researchers from any part of the world might also use the study to develop more comprehensive models for economic collation of countries to foster research activities and to benefit stake holders at large.

\section{Research Hypotheses}

H1A: There is a negative relationship between political insecurity and progress of CPEC

H2A: There is a negative relationship between ethnic separation and progress of CPEC

H3A: There is a negative relationship between internal security and Progress of CPEC

H4A: There is a negative relationship between corrupt bureaucracy and Progress of CPEC

H5A: There is a negative relationship between violence and progress of CPEC

H6A: There is a negative relationship between lack of properly trained workforce and Progress of CPEC

H7A: India's influence significantly moderates the relationship between political insecurity and progress of CPEC 
H8A: India's influence significantly moderates the relationship between ethnic separation and progress of CPEC

H9A: India's influence significantly moderates the relationship between internal security and progress of CPEC

H10A: India's influence significantly moderates the relationship between corrupt bureaucracy and progress of CPEC

H11A: India's influence significantly moderates the relationship between violence and progress of CPEC

H12A: India's influence significantly moderates the relationship between lack of properly trained workforce and Progress of CPEC

\section{Research Model}

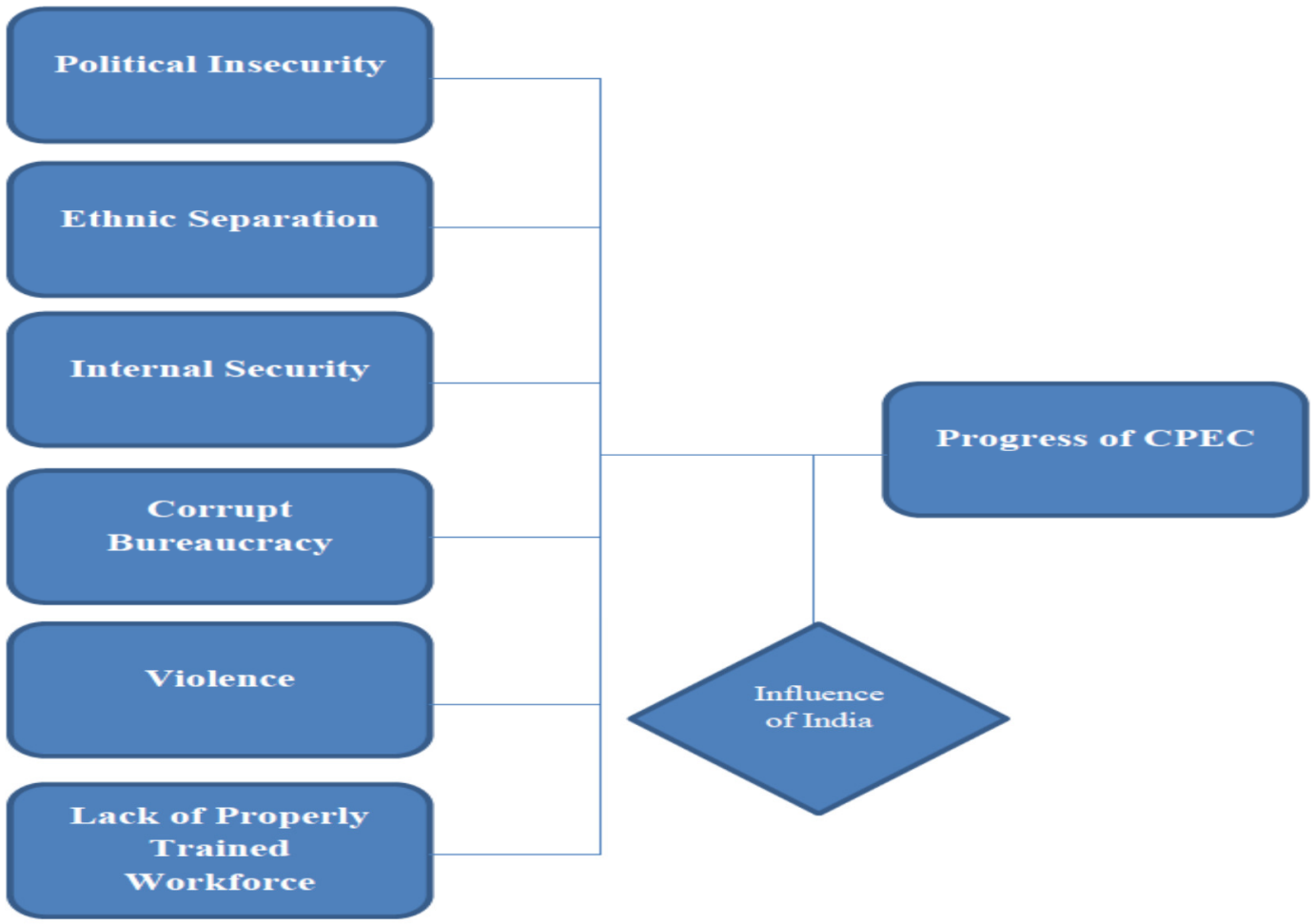

Figure 1 Proposed Model

\section{Literature Review}

Study posit a question that how Pakistan deal with terrorism, ethnic separation, political instability, religious extremism and foreign interference to foster CPEC? (Deling \& Diren, 2015). Especially when the country is a developing one and lacks in industrialization (Deng \& Li, 2017) therefore Chinese investors are legitimate to be worry about the progress of CPEC (Deling \& Diren, 2015). Hence legitimate to believe Deng and Li (2017) that issues mentioned above might foster negative thinking in nationals of Pakistan and might also affect Pak-China relationships. Considering all above mentioned points upcoming section will provide detailed review of potent variables associated with the point of interest:

\section{Political Insecurity}

One of the initial studies by Imtiaz Salman Kamal Shamraiz and Al Hinai (2016) postulated that internal stability is must for cultivation of real benefits associated with CPEC. Similar sort of indications given by Abbas et al (2017) that all political parties must resolve conflicts and play their part for achieving communal goal i.e. CPEC. Supported by the Khan (2018) that political instability of Pakistan is diminishing growth of the economy drastically which sometimes force army to get involve in public affairs.

Thus one must pay concern to the study of Idrees Shapiee Ahamat and Hanwei (2018) that CPEC projects might be cancelled due to continual politics of federalism. Study also indicated that any cancellation or abolishment due to local political dilemma or governance would result in violation of International commitments. Thus to prevent disintegration of CPEC we must raise concern towards establishment of political stability (Khan, 2018).

\section{Ethnic Separation}

One of the potent variable creating hurdles in the implementation of CPEC is domestic political struggle and obstruction (Ahmad \& Hong, 2017). These differences generated because of political economy where resource 
allocation has always been accompanied with political conflicts (Ali, 2015).

Study of Mirza et al (2017) also supported this postulate that some of the Baloch writers and academicians are in against of CPEC as they believe project will majorly favors Punjab. Hamid Khan Khaliq Ajmal (2017) also supported the point and posits that the clear cut economic agenda of CPEC has been transformed into political agenda by politicians and media. Ahmad and Hong (2017) also highlighted similar aspects that some opposition parties are continuously raising voice in against of almost every project of CPEC. Thus there is a substantive delay in the implementation of project (Hadi et al., 2018).

\section{Internal Security}

Study of Abbas et al (2017) posits that Pakistan's government must provide firm security to the Chinese workers working on the project. Further explained by Ahmad and Hong (2017) that militancy in Baluchistan is the issue of major concern for CPEC as security issues affect Chinese throughout the project (Abbas et al, 2017). Alhough according to Ahmad and Hong (2017) Baluchistan is the main hub which will connect Gwadar with Kashgar but perceived negatively by locals. Negativity is because of perception that the project is implemented in unjustified manner and in protest Baloch militants wants to disintegrate the progress of the project.

Similarly study of Mirza et al (2017) indicated that security conditions of Gilgit-Biltistan are also not suitable for working on the project of CPEC. Therefore it is optimal to believe that the security of the corridor is one of the most burning issues (Shah, 2018). Although armed forces are striving to resolve this problem but even then there are some issues obstructing the implementation of CPEC (Mirza et al., 2017). Therefore central government as well as all provincial government of all provinces is using their own forces to protect the project (Shah, 2018).

\section{Corrupt Bureaucracy}

Corruption is the part of the economy since the establishment of the country in 1947 (Javaid, 2010). Although corruption has its roots in the economy from the times of British Government which grants land and titles only to its loyalists (Awan, 2004). This vicious cycle of corruption also entails during the period of nationalization in 1970 and resulted in climax of corruption in business and religious circles (Javaid, 2010).

Therefore study of Ahmer (2014) postulated that corruption is one of the major threats in the implementation of CPEC and government must develop efective measures to deal with this. Similarly Ali (2015) demands transparency in projects of CEPC as ministries were reluctant in disclosing details to public without paying concern to the demands of political parties. Therefore recent study of Deng and $\mathrm{Li}$ (2017) posits that corrupt bureaucracy in Pakistan is restricting the progress of CPEC. Study also highlighted that corruption and bribe are major hindrances in the progress of CPEC with lacking in criteria of punishment pushing hurdles severely. Shah (2018) also indicated that government of Pakistan has not yet disclosed the master plan of the project. Hence it is appropriate to state that transparency of work has also not been addressed by top level bureaucrats \& government of Pakistan.

\section{Violence}

Hadi et al (2018) posits that continuous involvement of Pakistan in war against terror resulted in increased liability of CPEC towards Pakistan. Therefore in accordance with Javaid (2016) Pakistan must dismantle network of terrorists in order to overcome glitches of outsiders working on CPEC (Abbas et al., 2017).On the other side geostrategic position of Gwadar port and perception regarding its miss use also forces massive hurdle and creates continuous state of insurgency. Similar sort of conditions found in Khyber Pakhtunkhwa (KPK) where terrorism is disturbing locals as well as economic progress (Javaid, 2016).

\section{Lack of Properly Trained Workforce:}

Ali (2015) posits that in accordance with the magnitude and plans Pakistan will require intensively trained workforce to carryout CPEC. Although Pakistan ranked in top 10 countries with respect to labor force but lacks in proper labor force development. Although skilled, trained and physically fit labor force is the prerequisite for effective implementation of CPEC (Ahmad \& Hong, 2017). Deng and Li (2017) also highlighted the significance of labor and indicated the lacking of proper training institutions in Pakistan is extending the gap between technology and education.

\section{External Influence}

Study of Abbas et al (2017) indicated that external threats are also prevalent in the way of CPEC and there are multiple countries which are trying to pose negative impacts on CPEC. Although article of Khan (2018) indicated that among all the external challenges the most notable is extreme attitude of adjacent country India. Study of Javaid (2016) is supporting Khan and highlighted that Indian prime minister opposes the project openly during his visit to China. India also perceives China's collaboration with Bangladesh and Sri Lanka negatively thus trying to disturb CPEC. 
In fact in accordance with the study of Javaid (2016) Indian prime minister admits that their agency raw has a network in Baluchistan. Study of Shah (2018) indicated that government of Pakistan also admits that India and Afghanistan are the major cause behind subversive activities against CPEC especially in Baluchistan (Javaid, 2016).

\section{Research Design:}

The philosophy of research linked with this study is epistemology, supported by the study of Cohen Manion and Morrison (2007) that epistemology is associated with knowledge. Thus in coherence with Charmaz (2006), "Epistemology" has been used as the research philosophy of the study as the real purpose is to understand what exists in reality? And also to explain how knowledge base has been developed, therefore in coherence with the logic of epistemology and realism has been used as the research stance (Scotland, 2012). Method pursued for compilation of the study is deductive and the study settings were Non-Contrived while the unit of analysis was Individual (Sekran \& Bougie, 2016).

\section{Sampling Design}

Studies explored threats to CPEC are far and few between, especially there is severe lacking of studies from the context of Pakistan. Although some of the studies e.g. Abid and Ashfaq (2015), Ali et al (2018), Durrani (2017), Hussain (2016), Javed (2017) and Ahmad and Hong (2017) etc. explain the phenomenon in a conceptual way. This means all of prior studies mainly towards indication of issues related to CPEC hence none of these highlighted any specific data collection technique, sample size or statistical tools for analysis.

Hence in accordance to Deling and Diren (2015) public opinion is selected as the tool for data collection. This data collection method has also been used by Sultan, Ahmed and Zafar (2017) to collect opinion from youth. Therefore similar data collection approach is adopted for compilation of this study. Sample mainly collected from five major cities i.e. Karachi, Lahore, Islamabad, Peshawar and Quetta.

\section{Sample Size}

For pilot testing data was collected from 30 respondents from the major five i.e. 150 in total and the sample used for compilation of actual study was 1500 i.e. 300 from each city.

\section{Questionnaire}

A self-administrative questionnaire was developed as almost all the prior researches in this domain are qualitative in nature. Although to design questionnaire appropriately elements used by Deling Diren and Huang (2016) are used. Moreover to make study emphatic \& contemporary pattern, question and indications from prior studies are mixed with articles published in newspapers and electronic media.

Finally all the questions were transformed in to likert scale. Reason behind this adaptation is the indication of Likert (1932) that scale was developed to measure attitudes. Statement was supported by Revilla, Saris, and Krosnick (2014) that this type of instrument is applicable for gauging wide variety of constructs.

\section{Statistical Testing and Analysis}

According to the points mentioned above initially there is a requirement pilot testing in order to validate the research instrument (questionnaire). Therefore in accordance with Litwin (1995) the best method for measuring internal consistency is Cronbach Alphaa. Therefore values of Cronbach Alpha have been tested through taking the reference of Maiyaki and Mohd Mokhtar (2011) and reliability of research instrument has been evaluated for all the elements. Results of Pilot Study might be observed through Table 1.

\begin{tabular}{|c|c|c|}
\hline \multicolumn{2}{|l|}{ Reliability Statistics } & \\
\hline & No of Items & Cronbach's Alpha \\
\hline Progress of CPEC & 5 & 0.783 \\
\hline Lack of Properly Trained Workforce & 4 & 0.751 \\
\hline Violence & 4 & 0.791 \\
\hline Political Insecurity & 5 & 0.719 \\
\hline Corrupt Bureaucracy & 5 & 0.717 \\
\hline Internal Security & 4 & 0.761 \\
\hline Ethnic Separation & 5 & 0.772 \\
\hline Influence of India & 5 & 0.620 \\
\hline
\end{tabular}

Table 1 Reliability Values for Pilot Testing

Table 1 highlighted that value of Cronbach Alpha is more than 0.60 for each case. Therefore in accordance with Maiyaki \& Mohd Mokhtar (2011) it is legitimate to declare pilot test a successful and appropriate for the designed instrument. After successful pilot study testing researchers conduct the entire study on larger sample size 
1500 i.e. 300 from each city. Again the reliability of data has been check through Cronbach Alpha in order to affirm the data for further inferential testing. The reliability analysis for entire sample might be viewed in Table 2 . Moreover relationship might be further clarified from the Figure 2 which indicates the model of path analysis through second level confirmatory factor analysis.

\begin{tabular}{|l|c|}
\hline \multicolumn{2}{|c|}{ Reliability Statistics } \\
\hline Progress of CPEC & Cronbach's Alpha \\
\hline Lack of Properly Trained Workforce & $\mathbf{0 . 8 3 3}$ \\
\hline Violence & $\mathbf{0 . 8 5 1}$ \\
\hline Political Insecurity & $\mathbf{0 . 8 7 9}$ \\
\hline Corrupt Bureaucracy & $\mathbf{0 . 8 2 9}$ \\
\hline Internal Security & $\mathbf{0 . 8 1 7}$ \\
\hline Ethnic Separation & $\mathbf{0 . 8 6 8}$ \\
\hline Influence of India & $\mathbf{0 . 8 7 7}$ \\
\hline
\end{tabular}

\section{Table 2 Reliability Analysis}

Table 2 highlighted that value of Cronbach Alpha is more than 0.7 in every case. Therefore study proceeded towards inferential testing in accordance with Pietersen and Maree (2007) that value of Cronbach Alpha more than 0.7 is optimal. AMOS has been used in order to indicate effect of independent variables on the dependent variables although first task was to validate the research model. The values of model fit summary might be observed through Table 3

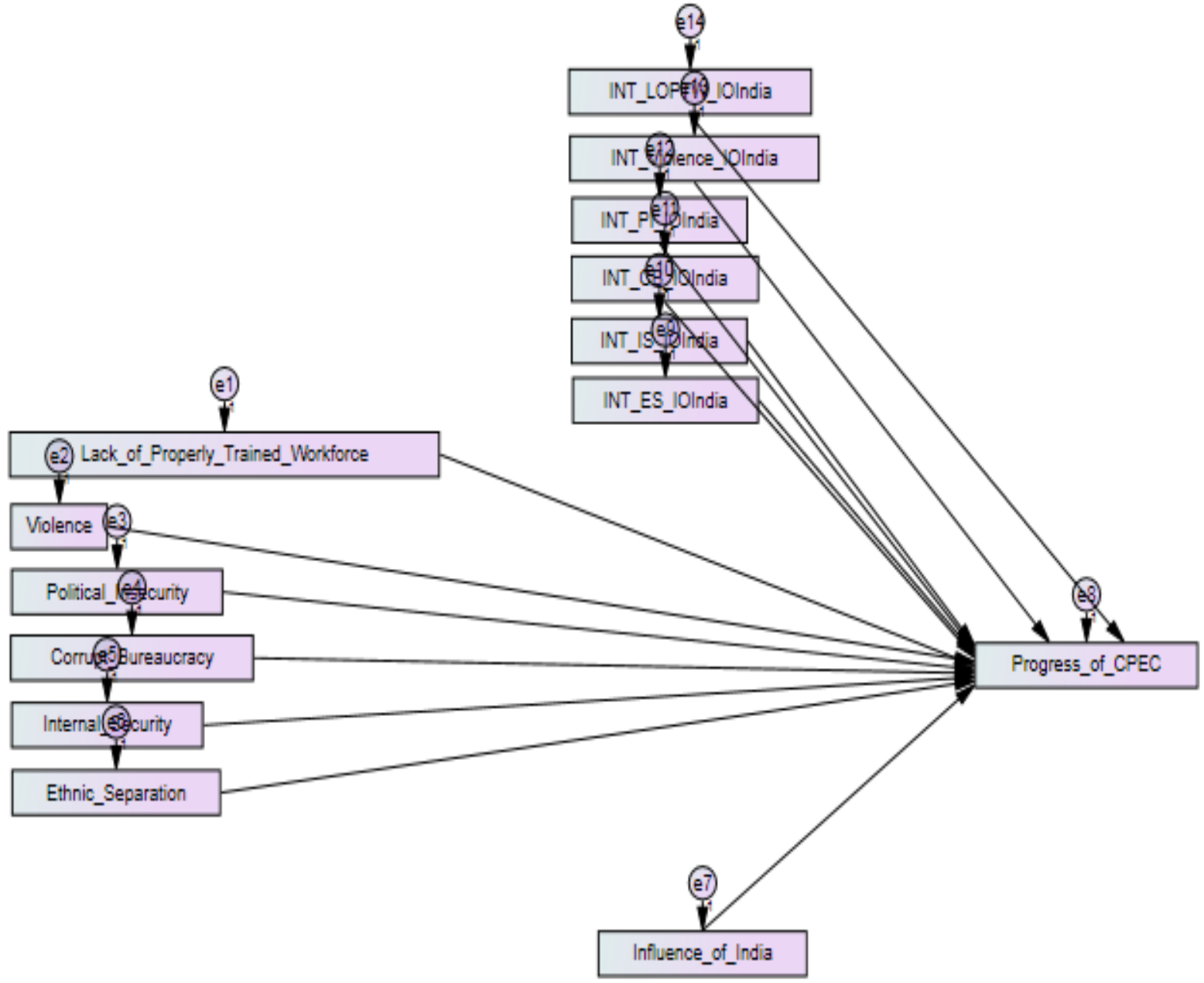

Figure 2 Path Analysis model for $2^{\text {nd }}$ level CFA

\begin{tabular}{|c|c|c|c|}
\hline CMIN/DF & GFI & CFI & RMSEA \\
\hline 1.983 & 0.901 & 0.925 & 0.03 \\
\hline
\end{tabular}

Table 3 Model Fit Summary

Table 3 amplifies three major determinants for the model fit and in accordance with Schumacker and Lomax 
(2004) all the majors are adequate enough to treat model as "Fit" for the study. Schumacker and Lomax also posits that acceptance region for Relative Chi-Square (CMIN/DF) must be lower than 2 (Kline, 1998) or 3 (Ulman, 2001). Similarly the range of Root Mean Square Average (RMSEA) must be less than 0.05.

Therefore values of Relative Chi-Square (CMIN/DF) and Root Mean Square Average (RMSEA) are appropriate to suggest the model as fit. Although Hooper Coughlan and Mullen (2008) posits that Confirmatory Fixed Index (CFI) is the measure which is used for "Model Fit" under most of the situations. Study also highlighted that the value of CFI must be greater than 0.90 (Hu \& Bentler 1999). Model used for this study has also been supplemented with a moderating variable therefore there is a need to evaluate each variable separately as well as in the presence of moderator. Hence second order CFA has been used for the purpose of analysis. The values for the estimate as well as probability (significant value) might be seen from Table 3.

\begin{tabular}{|c|c|c|c|c|c|c|}
\hline & & & Estimate & S.E. & C.R. & $\mathbf{P}$ \\
\hline Progress CPEC & $<---$ & Lack of Prop. Trained WF & -2.264 & .010 & -234.243 & .012 \\
\hline Progress of CPEC & $<---$ & Violence & 1.485 & .007 & -214.126 & .082 \\
\hline Progress of CPEC & $<---$ & Political Insecurity & -.137 & .007 & -20.857 & .002 \\
\hline Progress of CPEC & $<---$ & Corrupt Bureaucracy & -.041 & .006 & -6.635 & .001 \\
\hline Progress of CPEC & $<---$ & Internal Security & -.251 & .007 & -37.279 & .024 \\
\hline Progress of CPEC & $<---$ & Ethnic Separation & -1.826 & .010 & -191.149 & $* * *$ \\
\hline Progress of CPEC & $<---$ & Influence of India & -.430 & .007 & -65.848 & $* * *$ \\
\hline Progress of CPEC & $<---$ & INT LOPTW I of India & -.145 & .002 & -69.152 & $* * *$ \\
\hline Progress of CPEC & $<---$ & INT Violence I of India & -.263 & .002 & -128.523 & $* * *$ \\
\hline Progress of CPEC & $<---$ & INT PI I of India & -.008 & .005 & -1.692 & .042 \\
\hline Progress of CPEC & $<---$ & INT CB I of India & -.018 & .002 & -8.783 & $* * *$ \\
\hline Progress of CPEC & $<---$ & INT IS I of India & -.174 & .002 & -79.034 & $* * *$ \\
\hline Progress of CPEC & $<---$ & INT ES I of India & -.001 & .002 & -.656 & $* *$ \\
\hline
\end{tabular}

Table 3 Regression Weights

On the bases of values achieved through statistical testing it has been concluded that all the variables included in the study are affecting the performance of CPEC. Table also indicated that effect of each variable worsen with the inclusion of moderating variable i.e. influence of India.

\section{Conclusion}

Findings from youth of Pakistan aids in accepting all the alternative hypotheses developed for the analysis of public opinion. Thus reflected that there are several internal and external issues obstructing the progression of CPEC but internal set of issues is more impactful. Study supports almost entire set of authors cited in literature e.g. Abbas et al (2017), Ahmer (2014), Ahmad and Hong (2017), Idrees et al (2018), Imtiaz et al (2016) and Mirza et al (2017) etc. Therefore it is optimal to state that "Game Changer" project is facing massive issues. Study also affirms that India is the major obstacle from outside and in fact enlarging the impact of all the other obstacles (Abbas et al., 2017, Javaid, 2016 \& Khan, 2018).

\section{Areas for Future Research:}

Study provided basis for the scholarly writing and generation of research ideas. Thus through taking this research as the base other might carry research on the obstacles prevalent through secondary data (available).

Moreover findings might also be optimized by using moderating variables like obstacles like some of the western countries.

\section{References}

1. Aamir, A. (2018, July 25th). Religious violence jeopardises China's investment in Pakistan. Financial Times, https://www.ft.com/content/8810e618-9020-11e8-bb8f-a6a2f7bca546

2. Abbas, S., Shouping, L., Sidra, F., \& Sharif, A. (2018). Impact of Crime on Socio-Economic Development: A Study of Karachi. Malaysian Journal of Social Sciences and Humanities (MJSSH), 3(3), 148-159.

3. Abid, M., \& Ashfaq, A. (2015). CPEC: Challenges and opportunities for Pakistan. Journal of Pakistan Vision, 16(2), 142-169.

4. Ahmad, R., \& Hong, M. (2017). China-Pakistan economic corridor and its social implication on Pakistan: How will CPEC boost Pakistan's infrastructures and overcome the challenges. Arts and Social Sciences Journal, 2, doi 10.4172/2151-6200.1000265

5. Ahmar, M. (2014). Strategic meaning of the China-Pakistan economic corridor. Strategic Studies, 34(4/1).

6. Ali, A. (2015). China Pakistan Economic Corridor (CPEC): Prospects and challenges for regional integeration. International Journal of Social Sciences and Humanity Studies, 7(1), 1-15. 
7. Ali, R., Ali, W., Ali, M., Raza, B. and Niazi, A. A. K., (2018). China-Pak Economic Corridor (CPEC): Economic Transformation-Challenges and Opportunities for the Local Residents. Journal of Politics and International Studies, 4(1), 17-30

8. Awan, M. K. B. (2004). Anti-corruption strategies in Pakistan. Bookbiz.

9. Butt, K. M., \& Butt, A. A. (2015). Impact of CPEC on Regional and Extra-Regional Actors. The Journal of Political Science, 33, 23.

10. Butt, K. M., \& Butt, A. A. (2015). Impact of CPEC on Regional and Extra-Regional Actors. The Journal of Political Science, 33, 23.

11. Cavana, R. Y., Delahaye, B. L., \& Sekaran, U. (2001). Applied business research: Qualitative and quantitative methods. John Wiley \& Sons Inc

12. Charmaz, K. (2006). Constructing grounded theory: A practical guide through qualitative analysis. Sage.

13. Cohen, L., Manion, L., Morrison, K., \& Morrison, R. B. (2007). Research Methods in education, Rout ledge.

14. Deling, H. \& Diren, L. (2015). The Analysis of Public Opinion About China-Pakistan Economic Corridor. Proceedings of International Conference on CPEC, GC University, Lahore

15. Deling, H., Diren, L., \& Tiantian, H. (2016). Analysis of Public Opinion About China-Pakistan Economic Corridor. Journal of Applied Sciences, 16(6), 286-292.

16. Deng, A., \& Li, Y. (2017). Problems and Countermeasures in the Development of Transport Logistics in China-Pakistan Economic Corridor. World Journal of Research and Review, 5(6), 75-81

17. Deng, A., \& Li, Y. Problems and Countermeasures in the Development of Transport Logistics in ChinaPakistan Economic Corridor. World Journal of Research and Review, 5(6).

18. Durrani, M. Z., Sami-Ullah, Khan, I., Irfan, K. \& Raza, B. (2017). Roads to Economic Growth: A ChinaPakistan Roads to Economic Growth: A China-Pakistan Economic Corridor Perspective, Academic Journal of Social Sciences, 1(3), 235 -243

19. Hadi, N. U., Batool, S., \& Mustafa, A. (2018). CPEC: An Opportunity for a Prosperous Pakistan or Merely a Mirage of Growth and Development. Dialogue (Pakistan), 13(3), 295-311

20. Hamid, M, Khan, H. S., Khaliq, A. \& Ajmal, M. (2017). Role of CPEC in the Economy of Pakistan along with its Threats. International Journal of Scientific \& Engineering Research, 8(1), 536-549

21. Hussain, E. (2017). China-Pakistan economic corridor: will it sustain itself?. Fudan Journal of the Humanities and Social Sciences, 10(2), 145-159.

22. Idrees, R. Q., Shapiee, R., Ahamat, H., \& Hanwei, L. (2018). How Logistics Investment Arrangement is a Key Concern to China-Pakistan Economic Corridor (CPEC)? A Legal and Policy Analysis of CPEC Logistics Investment Model and Future Challenges for Pakistan. International Journal of Asian Social Science, 8(11), 1059-1067.

23. Imtiaz, Salman, Kamal, Shamraiz and Al Hinai. (2016). China Pakistan Economic Corridor (CPEC): Prospects, Opportunities and Challenges. Opinion, 75-89.

24. Jaccard, J., Wan, C. K., \& Jaccard, J. (1996). LISREL approaches to interaction effects in multiple regression (No. 114). Sage

25. Jaleel, S., \& Bibi, N. (2017). Baloch Insurgency and its impact on CPEC. University Library of Munich, Germany.

26. Javaid, U. (2010). Corruption and its deep impact on good governance in Pakistan. Pakistan Economic and Social Review, 123-134.

27. Javaid, U. (2016). Assessing CPEC: Potential threats and prospects. Journal of the Research Society of Pakistan, 53(2). 254-269

28. Jian, L. (2015). India's Attitude Toward CPEC and China's Countermeasure. Proceedings of International Conference on CPEC, GC University, Lahore.

29. Khaliq, A. (2018, April 16 ${ }^{\text {th }}$ ). Is Pakistan falling into China's debt trap?, Committee for the Abolition of Debt, http://www.cadtm.org/Is-Pakistan-falling-into-China-s

30. Khan, N. A. (2018, Nov 15). Internal and external challenges \& CPEC. Pakistan Observer, https://pakobserver.net/internal-and-external-challenges-cpec/

31. Kline, R. B. (1998). Principles and practice of structural equation modeling. Guilford Press.

32. Likert, R. (1932). A technique for the measurement of attitudes. Archives of psychology, 22 (140), 55

33. Maiyaki, A. A., \& Mohd Mokhtar, S. S. (2011). Determinants of customer behavioural responses: A pilot study. International business research, 4(1), 193-197.

34. McMillan, J. H. and Schumacher, S., (2006), "Research in Education” $6^{\text {th }}$ Ed., Pearson, New York.

35. Mengsheng, T. (2015). How to Design the Layout of China-Pakistan Economic Corridor. Proceedings of International Conference on CPEC, GC University, Lahore.

36. Mirza R. I., Azem, K., Waheed, N., and Zehra, K. (2017). China Pakistan Economic Corridor - An Economy booster for Pakistan, Journal of Developing Country Studies, 7(3), 41-49

37. Pietersen, J., \& Maree, K. (2007). Statistical analysis II: Inferential statistics. First steps in research. Pretoria: 
Van Schaik, 197-213.

38. Revilla, M. A., Saris, W. E., \& Krosnick, J. A. (2014). Choosing the number of categories in agree-disagree scales. Sociological Methods \& Research, 43(1), 73-97.

39. Scotland, J. (2012). Exploring the Philosophical Underpinnings of Research: Relating Ontology and Epistemology to the Methodology and Methods of the Scientific, Interpretive, and Critical Research Paradigms. English language teaching, 5(9), 9-16

40. Sekaran, U., \& Bougie, R. (2016). Research methods for business: A skill building approach. John Wiley \& Sons.

41. Shah, A. R. (2018). How Does China-Pakistan Economic Corridor Show the Limitations of China's 'One Belt One Road'Model. Asia \& the Pacific Policy Studies, 5(2), 378-385

42. Sultan, M. F., Ahmed, I. \& Zafar, M. R. (2017). Measuring the Impact of China Pakistan Economic Corridor on the Socio-Economic Aspects of Pakistan: A Quantitative Research Highlighting the Public Opinion. Journal of Economics and Sustainable Development, 8(23), 46-56

43. Ullman, S. (2001). In BG Tabachnick, \& LS Fidell (Eds.), Using multivariate statistics (pp. 653-771 ed., p. 966). 